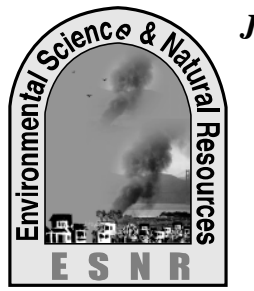

J. Environ. Sci. \& Natural Resources, 6(2): 43-47, 2013

ISSN 1999-7361

\title{
Impact of SIDR on Peoples' Adaptation in Some Selected Villages of Pirojpur District of Bangladesh
}

\author{
F. R. Moni, A. Sultana, M. S. Rumi, B. S. Nahar, R. Khatun and M. A. Baten
}

Department of Environmental Science, Bangladesh Agricultural University,Mymensingh-2202

\begin{abstract}
A survey was conducted to get an overview and to gather information on the existing and socioeconomic condition of the SIDR affected people and migration. To perform this study data were collected from the three selected village (south Shailkati, Hothkhali and Lahori) affected people by random sampling after selecting the study topic and area. Then the data were processed and analyzed through using different statistical tools like pie-chart, bar diagram, table etc. The GoB and NGO's subsidiaries, also help the SIDR victims to cope with the situation. From the study we found that the NGO's contributed more to adapt with the situation. After SIDR the occupation of non-agriculture day-labour increased (37\%) and the occupation of agriculture decreased $31 \%$ from $55.64 \%$. After SIDR middle income group people were greatly affected. The income and expenditure of middle income group people were found to reduce. Low income group people increased their income and expenditure was decreased. After SIDR due to decrease their average income, they could not manage their basic needs. The food habit of the affected people was also changed. They took more flour rather than rice. The scarcity of agricultural production created the reduction of food stock. Most of the respondents had no food stock. The rate of internal migration was also increased. The rate of migration to other places $(47 \%)$ and Dhaka (53\%) was increased due to SIDR. But the situation was better than close post SIDR period. Most of the cases they are adopting with the changing socio-economic conditions.
\end{abstract}

Key words: Impact, people, Pirojpur, SIDR

\section{Introduction}

SIDR, a tropical revolving storm is commonly known as cyclone in the part of the world. SIDR was recorded as one of the 10 fiercest cyclones that had hit the coastal regions of Bangladesh in the 131 years between 1876 and 2007. The word 'SIDR' originates from the official language of Srilanka 'Sinhalese' is commonly understood an 'eye'. The SIDR, the terrible eye, had rushed with great signal number 10 and smashed the entire southern districts on the fateful night of November 15, 2007. The storm arrive as a category-4 Super Cyclone with peak winds of $250 \mathrm{~km} / \mathrm{h}$, affecting approximately 30 districts within the administrative divisions of Barisal and Khulna (Hasan, 2009; Banglapedia, 2010). According to Government estimate 5,64,967 households and 9,57,110 were partially damaged in 30 affected districts. Livelihood were affected mainly by damage to income generating assets and by loss of employment and income such as industrial equipment, the tools of self employed workers, destruction of common assets, loss of shop inventories, destruction of shop or business premises and loss of income-earning human capital in many of the households through disaster related death. A total of 5,67,000 persons were affected in their employment by SIDR, among them $1,60,000$ persons temporarily or permanently lost their source of income in non agricultural establishments, along with another $1,34,000$ self employed workers. This overall corresponds to approximately 4,36,000 households were affected, with an average 1.3 persons per households in the labor force. In the four most affected districts, there were 32,000 workers were affected corresponding approximately to 250000 households or $25 \%$ of all households in that area (Khan et al., 2007; Cyclone, SIDR in BD, 2008; Philip Gain 2008; Banglapedia, 2010). Therefore, in this study I am going to find out the existing socio-economic condition and as certain the problem created by the losses of crop and present trend of adaptation with the nature, lives and livelihood of those victims due to SIDR in 2007 in selected villages (South Shailkathi, Hothkhali and Lahori) of Pirojpur districts in Bangladesh."The impact and adaptation by people through community based adaptation techniques was attempted to find out". This learning will help us to give an insight for taking future course of action. It's also providing us the real scenario of people community based adaptation techniques for facing environmental hazards. Trough this leanings we can take environmental policy level decisions for ensuring sustainable development. Considering the above views in mind the present work was designed in three selected villages of Pirojpur districts with the following objectives:

1. To find out the people adaptation with the environment and its current trends during post SIDR period.

2. To find out the rate of migration due to SIDR.

\section{Methods and Materials}

\section{Selection of the study area}

The study area is located beside the river Balasher in the south-western coastal region of Bangladesh that is more affected area and DAE officials told the adviser that the south and southwestern districts have suffered heavy loss in vegetables, crops and houses. The damages in 
three villages South Shailkathi, Hothkhali and Lahori under the upazilla of Bhandaria, Pirojpur Sadar and Mothbaria under Pirojpur district respectively was estensive.

\section{Characteristics of the respondents in selected villages}

\section{Farmer's name}

Farmer name were included in the interview schedule.

\section{Level of education}

Education level of the respondents was measured by the number of years of schooling he or she completed. The level of education score of a respondent was determined for his response to (1) No education (2) capable to sign (3) Primary (4) Secondary (5) Higher.

\section{Family size}

Family size of a respondents was measured by the number of his family member including himself, children, wife and parents.

Age

The age of respondents refers to the period of time from his birth to the time of interview.

\section{Income}

For study purpose the respondent incomes were divided into three livels (1) Low income group (1-4000 Tk.) (2) Middle income group (40018000 Tk.) (3) High income group (8001-10000 Tk.).

Location of the study area: It is shown in table 1.

Table 1. Location of the study area

\begin{tabular}{|l|l|l|l|}
\hline Upazila & Union & villages & Number of household \\
\hline Bhandaria & Nodmulla & South Shailkathi & 40 \\
\hline Mothbaria & Sapleza & Hotkhali & 40 \\
\hline Zianagar & Balipara & Lahori & 40 \\
\hline & & Total & 120 \\
\hline
\end{tabular}

Source: Zilla parishad, Pirojpur, 2010

\section{Preparation of interview schedule}

Interview schedule was prepared with different parameter such as farmer's name, occupation, level of education, family size, age, farm size, changes in production of crop, damages in crop, impact on food habit, changes in food habits due to SIDR, total income \& total expenditure of the respondents before and after SIDR, duration of sufficient household food stocks, food shortage problem and meet the food demand during disaster, sources of rice for eats and how they are adapted with this natural disaster.

\section{Sample size determination}

The large group of individuals is known as population and the subset is known as the sample. The sample design refers to the techniques or procedures, the researcher would adopt in selecting items for the sample. At first I collected 40 Sidr affected people list from SAAO from each village's i.e total 240 people who are related with crop by different way. Then I took $40 \%$ people from each village by random sampling and the total respondent number was 120 .

\section{Data collection phase}

Collection of data: This study was mainly based on primary data. Secondary data were will be collected to supplement primary data.

\section{Primary data collection}

Primary data was collected through a structured interview schedule. A interview schedule survey was conducted through a direct field survey to collect the required data. In this process, the respondents were requested to answer the questions, carefully and honestly, regarding their socio-economic condition and the extent and problems of involvement in economic activities.

\section{Secondary data collection}

Data were collected from relevant books and journals, articles of different writers, seminar, thesis papers and Internet, different agencies.

\section{Analysis phase}

\section{Data processing and interpretation}

A survey with interview schedule was conducted to gather information from both primary and secondary sources. Then that data were processed and analyzed through using different statistical tools like pie-chart, bar-diagram, table etc. Several computer based software e.g. Microsoft excel; SPSS were used for processing data. After that necessary text document was included for the report.

\section{Analysis of collected data}

Different analytical tools have been applied for this study. Descriptive analyses explain by the analytical tools were SPSS, MS Excel are the required programs. Analysis shown by the charts and graphs perform by the Ms Excel. 


\section{Results and Discussion}

Before SIDR $38.34 \%$ people would earn a lowest amount of money (1-4000 Tk.) but after SIDR income of the lowest income group people has been increased from $38.34 \%$ to $44.34 \%$ people.
Again income of the middle income group people would earn (4001-8000 Tk.) but after SIDR income of the middle income group people has been decreased $50 \%$ to $45 \%$. Income of the high income group people has been decreased $11.66 \%$ to $10.66 \%$ (Table 2 ).

Table 2. Ranges of income of the respondents (\%) before and after SIDR in per month

\begin{tabular}{|l|l|l|}
\hline \multirow{2}{*}{ Household income range (Taka) } & \multicolumn{2}{|c|}{ Percent of respondents } \\
\cline { 2 - 3 } & \multicolumn{1}{|c|}{ Pre SIDR } & \multicolumn{1}{|c|}{ Post SIDR } \\
\hline $\begin{array}{l}1-4000 \\
\text { (Low income group) }\end{array}$ & 38.34 & 44.34 \\
\hline $\begin{array}{l}\text { 4001-8000 } \\
\text { (Middle income group) }\end{array}$ & 50 & 45 \\
\hline $\begin{array}{l}8001-10000^{+} \\
\text {(High income group) }\end{array}$ & 11.66 & 10.66 \\
\hline Total & 100 & 100 \\
\hline
\end{tabular}

Assessments of the changes in expenditure pattern of the respondents compare to pre SIDR period

Expenditure of the low income group has been decreased in that area. Before SIDR 58\% people expenditure was lowest amount of money (14000 Tk.). After SIDR $51 \%$ of the people expenditure were lowest income group people has been decreased from $58 \%$ to $51 \%$ people. Again middle income group people expenditure were middle amount money (4001-8000 Tk.) decreased from $30 \%$ to $25 \%$. But high income group people expenditure has been increased $12 \%$ to $24 \%$ (Table 3).

Table 3. Total expenditure of the respondents (\%) before and after SIDR in per month

\begin{tabular}{|l|l|l|}
\hline \multirow{2}{*}{ Household expenditure range (Taka) } & Percent of respondents \\
\cline { 2 - 3 } & Pre SIDR & Post SIDR \\
\hline $\begin{array}{l}1-4000 \\
\text { (Low income group) }\end{array}$ & 58 & 51 \\
\hline $\begin{array}{l}\text { 4001-8000 } \\
\text { (Middle income group) }\end{array}$ & 30 & 25 \\
\hline $\begin{array}{l}8001-10000^{+} \\
\text {(High income group) }\end{array}$ & 12 & 24 \\
\hline Total & 100 & 100 \\
\hline
\end{tabular}

Assessment of public and private subsidies during post SIDR period

Maximum (48.33\%) respondent got more housing materials from NGOs than GoB subsidies. About $16.66 \%$ respondents claimed that they built new house using money of their own during post SIDR (Table4). In case of fishing net, NGO's supported to buy $84 \%$ fishing net during post SIDR and about $16 \%$ of the respondent got to buy fishing net from others (Table 4). From this survey it was also found that only $17.12 \%$ of the respondents got subsidies in buying fishing boat from GoB, $47.44 \%$ got loan to buy fish boat from NGO's and others (35.44\%) of the respondents bought fishing boat by their own initiative. Very few respondents $(8.13 \%)$ got subsidies for cattle and $42.47 \%$ of the respondent got cash subsidies from GoB (Table 4). About $(10.33 \%)$ of the respondents managed cash and $43.33 \%$ of the respondents bought cattle by their own initiative and about $48.54 \%$ respondents got cattle and $45 \%$ respondents got cash from NGO's (Table4).

Table 4. Distribution of public and private subsidies during post SIDR period

\begin{tabular}{|l|l|l|l|l|l|}
\hline Name of subsidies & $\begin{array}{l}\text { GOB } \\
(\mathbf{\%})\end{array}$ & $\begin{array}{l}\text { NGO } \\
(\mathbf{\%})\end{array}$ & Relatives $(\mathbf{\%})$ & $\begin{array}{l}\text { Own } \\
(\mathbf{\%})\end{array}$ & $\begin{array}{l}\text { Other } \\
(\boldsymbol{\%})\end{array}$ \\
\hline House & 35 & 48.33 & 0.00 & 16.66 & 0.00 \\
\hline Fishing Boat & 17.12 & 47.44 & 0.00 & 35.44 & 00.00 \\
\hline Net & 0.00 & 84.00 & 0.00 & 0.00 & 16.00 \\
\hline Cattle & 8.13 & 48.54 & 0.00 & 43.33 & 0.00 \\
\hline Money & 42.47 & 45.00 & 0.00 & 10.33 & 0.00 \\
\hline
\end{tabular}


Assessment of status of meeting primary needs during the post SIDR period

Table 5. clearly shows that maximum $(35.02 \%)$ of the respondent had got their food from NGO's than GoB (25.83\%). About $20.58 \%$ respondent had the own to meet food, about $15.25 \%$ of the respondents replied that they manage it from the relatives and $3.32 \%$ of respondents said that the mange it from other sources. To meet the crisis of cash money, $15.85 \%$ of the respondent said that they got it from the GoB, $58.25 \%$ of them replied they got it from the NGO's, $22.75 \%$ of the respondent said that they had the own to meet it, $2.50 \%$ of the respondent replied that they got it from the relatives and other $0.66 \%$ of the respondent said that they got it from other sources (Table 5). Majority of the respondents got drinking water $(45.83 \%)$, cloths $(55.25 \%)$ and shelter $(48.85 \%)$ from NGO's and about $50 \%$ drinking water, $22.5 \%$ cloths and $27.25 \%$ shelter from GoB. About $4.17 \%$ drinking water, $22.25 \%$ cloths and $23.9 \%$ shelter, were brought by their personal initiative. They got minimum help from other sources (Table 5).

Table 5. Distribution of primary need during the post SIDR period

\begin{tabular}{|l|l|l|l|l|l|}
\hline $\begin{array}{l}\text { Name } \\
\text { of the } \\
\text { primar } \\
\text { y need }\end{array}$ & $\begin{array}{l}\text { GOB } \\
\%\end{array}$ & $\begin{array}{l}\text { NGO } \\
\%\end{array}$ & Personal\% & Relatives\% & Other\% \\
\hline Money & 15.85 & 58.24 & 22.75 & 2.50 & 0.66 \\
\hline Food & 25.83 & 35.02 & 20.58 & 15.25 & 3.32 \\
\hline Water & 50.00 & 45.83 & 4.17 & 0.00 & 0.00 \\
\hline Cloth & 22.5 & 55.25 & 22.25 & 0.00 & 0.00 \\
\hline Shelter & 27.25 & 48.85 & 23.9 & 0.00 & 0.00 \\
\hline
\end{tabular}

Assessment of the change in occupation profile due to SIDR

After SIDR majority (37\%) of respondent adopted in non agricultural day labor work than the pre-SIDR (16\%). Agricultural cultivation practices reduced to $31 \%$ than pre-SIDR $(55.64 \%)$ condition. Agriculture day labor work increased to $32.36 \%$ than the pre-SIDR $(28.36 \%)$ in Fig.1.

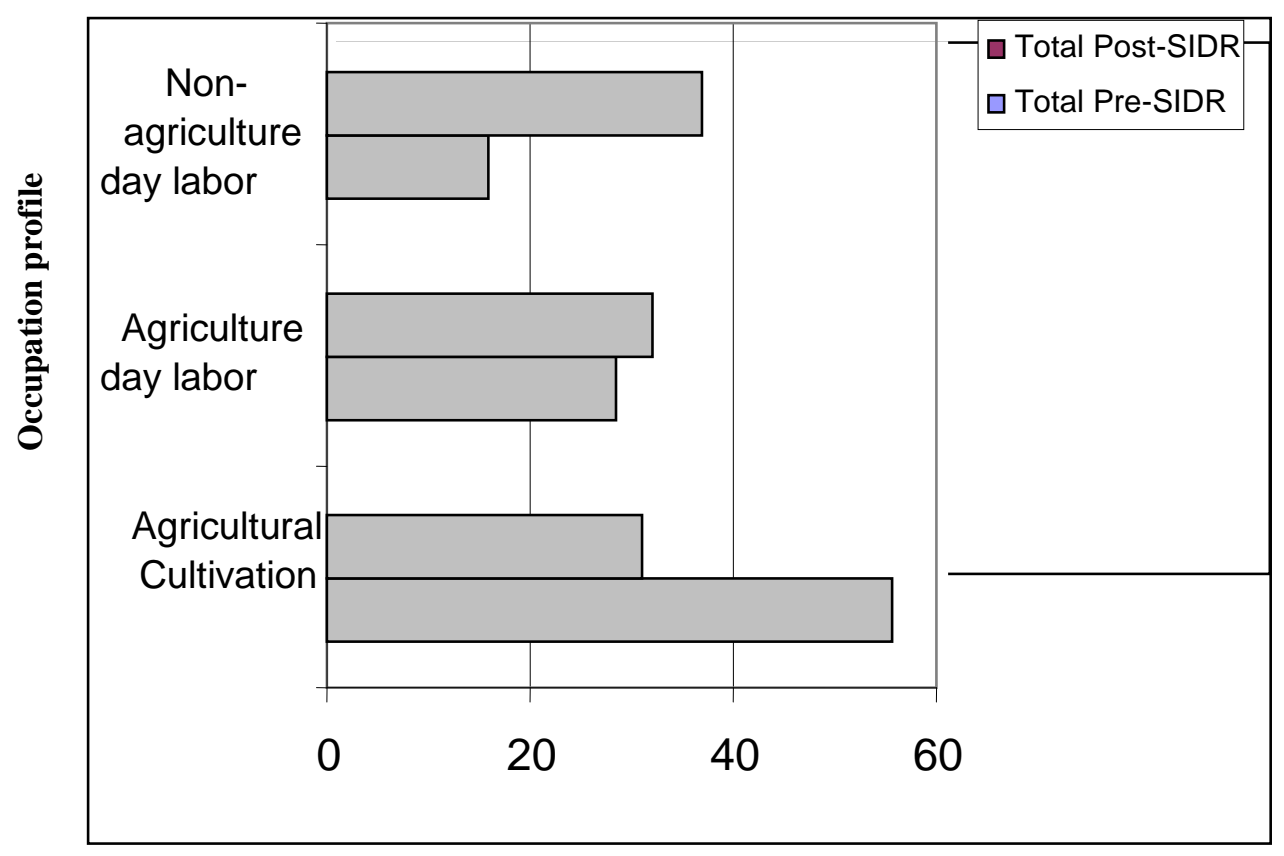

Percentage $(\%)$

Fig. 1: Change of agriculture profession after SIDR (Appendix VI)

Assessment of the impact on migration of SIDR affected people due to SIDR
From the study it was found that the migration rate of the SIDR affected people in Dhaka 
increased $53 \%$ to $35 \%$ and migrated to abroad reduce than the pre SIDR. The migration to other places increased $47 \%$ than the pre-SIDR $40 \%$ in Fig. 2.

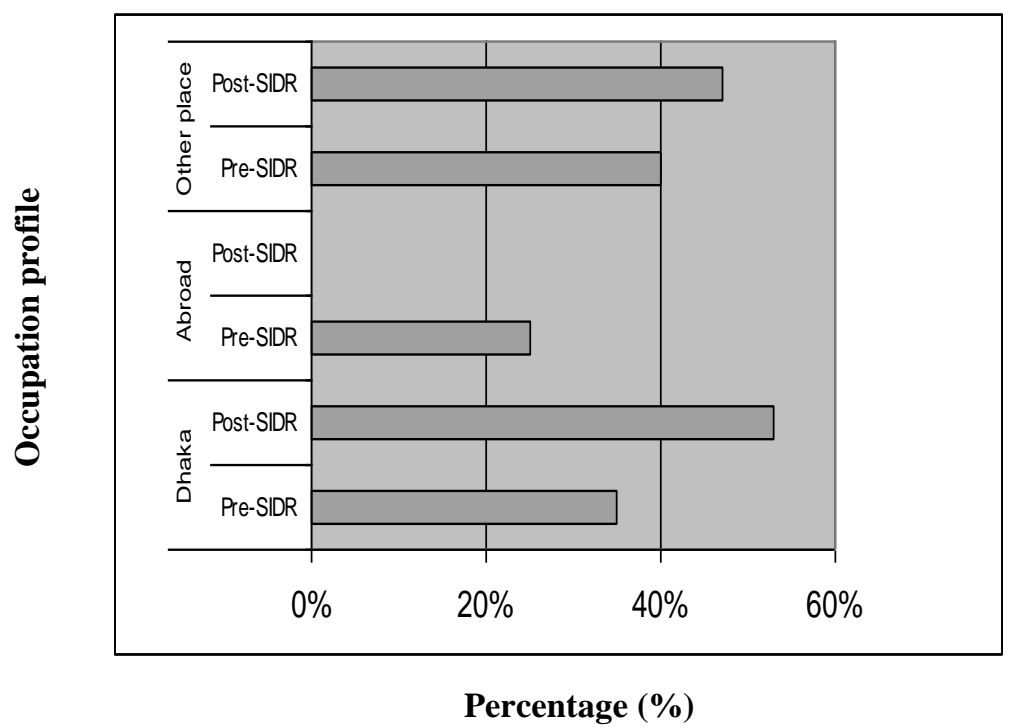

Fig. 2: Trend of people migration due to during pre and post SIDR

There is also some temporary migration in other places like Dhaka and other cities. This migration occurred due to unavailability of work and reduction of production. From the study we found

\section{Conclusion}

The level of living standard of respondent decreased due to decrease of production reduced the average income and expenditure, after SIDR. SIDR changed the profession of the affected people. The migration rate of SIDR affected area was increased. To meet their primary needs they were depended on NGO's, GO and other organizations. So SIDR has created a great impact on crop, livestock, fisheries and peoples' adaptation to it in some villages of Pirojpur district of Bangladesh.

\section{References}

Banglapedia 2010. National Encyclopedia of Bangladesh at http://en. banglapedia. org/ Cyclone_SIDR. PP. 2-3

Cyclone SIDR in Bangladesh, 2008. Damage, Loss and Needs Assessment For Disaster recovery and Reconstruction. Economic Relations Division. Ministry of Finance. Dhaka, Bangladesh. pp. 4346.

Hasan, 2009. 'Impact of SIDR on croplivestock-fisheries in some selected villages of Jhalokati district of Bangladesh', Master Thesis, Bangladesh Agricultural University (BAU), Mymensingh. PP.1-27 that the rate of migration increased during the post SIDR period.

Khan, Ashfaq Wares, Hasan, Rashidul, Hossain and Sohrab. 2007. "21 November, Acute Shortage of Drinking Water: Huge health crisis looms large". The Daily Star (The Daily Star (Bangladesh)). Front page.

Philip Gain 2008. 'SIDR and the Sunderbans: Impact of a Cyclone', The south Asian, http: //www. the south asian.org/ar chives/2008/sidr_and_the_sunderbans_ impact_1.html. 